\title{
Macular Hole Association and Behçet's Disease
}

\author{
Sow AS ${ }^{\star}$, Ndiaye JM, Kane H, Thiaw A, Nguer M, Ka AM, Diagne JP, Ndoye Roth PA, Ba EA \\ Doctor at the hospital Aristide Le Dantec Dakar
}

*Corresponding author: Sow AS, Doctor at the hospital Aristide Le Dantec de Dakar, E-mail: sadikh_sow@yahoo. fr

Received Date: November 15, 2018; Accepted Date: December 06, 2018; Published Date: December 08, 2018

Citation: Sow AS (2018) Macular Hole Association and Behçet's Disease. J Ophthalmol Open Access 2: 1-3

\section{Introduction}

Behçet's disease is an idiopathic systemic inflammatory disease characterized by intraocular inflammation, oral and genital ulceration, skin lesions and many other visceral disorders [1]. The purpose of our study was to report a case of macular hole in a 41-year-old patient with Behçet's disease who was admitted to the Ophthalmology Department of the EPS Dantec for a period of 24 days in charge of a bilateral pan-uveitis hypopion. We report the case of a 41-year-old patient with a history of right-sided unilateral uveitis, hospitalized for bilateral hypopion pan-uveitis. The patient was followed at the same time in Dermatology for a Behçet disease diagnosed and treated with Colchicine (Colchimax) for three years.

\section{Observation}

The ophthalmologic examination at the entrance noted a visual acuity quantified at a light perception in both eyes. The slit lamp examination in the right eye revealed diffuse conjunctival hyperemia, a hypopionic slide in the anterior chamber, an isflexic miosis, and IOP of $32 \mathrm{mmHg}$. After pupillary dilation, irido-crystallinic synechiae appeared in infero-nasal with iris pigments on the anterior capsule of the lens. The examination of the fundus found a hyalite with three crosses $(+++)$ which prevented a good view of the posterior pole. In the left eye, slit lamp examination also revealed diffuse conjunctival hyperaemia, a hypopionic slide in the anterior chamber, a medicated semi-mydriasis with a decreased photomotor reflex, an IOP of $28 \mathrm{mmHg}$ and posterior capsular opacity. Examination of the fundus with a 90 diopter lens (volk) indicated a hyalite with three crosses $(+++)$ preventing visualization of the posterior pole. On paraclinical examination, the biology revealed a nonspecific biological inflammatory syndrome made of an acceleration of SV and increased CRP. Fluorescein angiography and macular optic coherence tomography were not possible because of significant bilateral hyalitis in ad-

(C)2018 The Authors. Published by the JScholar under the terms of the Creative Commons Attribution License http://creativecommons.org/licenses/by/3.0/, which permits unrestricted use, provided the original author and source are credited. dition to posterior subcapsular cataract in the left eye. The dermatological examination was found at the mouth, ulcerations of about 4 to $5 \mathrm{~mm}$ in diameter, the bottom was lined with a coating of "fresh butter" appearance, associated with pustules and sitting at the anterior edge of the language. Examination of the genital tract found these same lesions in the scrotum and the inner thighs. Elsewhere, the examination of the other apparatuses was without particularities. The patient had received boluses of corticosteroid at a rate of $15 \mathrm{mg} / \mathrm{kg} /$ day for three days, an antibiotic-corticosteroid eye drops (1 drop five times a day) and ointment (an application at bedtime), a cycloplegic at a rate of a drop twice a day, a betablocker at a rate of one drop twice a day. The per-bone relay was based on corticosteroid therapy with prednisone (Cortancyl $20 \mathrm{mg}$ ) at the dosage of three tablets in the morning at 8 o'clock for six weeks and then at degressive doses; a platelet antiaggregant (Aspégic $250 \mathrm{mg}$ ) at 250 $\mathrm{mg}$ per day; cyclosporine (Neoral $50 \mathrm{mg}$ ) at a rate of two tablets per day. On the 21st day of hospitalization, the patient presented: in the right eye: a visual acuity coded at CLD at $2 \mathrm{~m}$, diffuse conjunctival hyperemia, corneal edema preventing an assessment of anterior chamber condition and IOP of $26 \mathrm{mmHg}$. The fundus was inaccessible. To the left eye: a visual acuity coded at CLD at $1 \mathrm{~m}$, an eye without inflammatory signs with an eye tone at $14 \mathrm{mmHg}$, a posterior subcapsular cataract, an absence 
of hyalite and a macular hole the size of a half-diameter papillary. Macular optic coherence tomography and fluorescein angiography were still obstructed in the right eye by corneal edema and hyalitis. In her left eye, she was visualizing a stage 4 macular hole.

\section{Comments}

The ocular involvement of Behçet's disease is one of the criteria for classifying this disease. Uveitis is one of the most common manifestations after oral aphtosis, and its establishment within two to three years after the latter is often the point of appeal for the diagnosis of the disease [2]. Maculopathy in Behçet's disease is common, observed in 16 to $50 \%$ of cases according to the authors $[3,4]$. These macular lesions must be known and detected quickly in order to establish an adequate treatment. The main macular retinal lesions are [5]. cystoid macular edema in the foreground (50\%), macular ischemia (19.4\%) of unfavorable functional prognosis secondary to occlusive vasculitis, epiretinal membranes (17\%) , subretinal neovascularization [6]. pseudoholes and macular holes. These are very rare, estimated at about 2.3\% [7]. For Shikano and Shimizu [8,9]. macular involvement would be constant in the presence of ophthalmological involvement during Behçet's disease. Its frequency is underestimated because of the associated ocular lesions (anterior uveitis, cataract, hyalite, posterior synechiae) which hinder the visibility of the fundus. Indeed, the evaluation of the macular state is difficult during the outbreaks due to opacification of the media. This is why the macular state must be evaluated during the period of remission. Cystoid or non-cystoid macular edema occurs in 20 to $75 \%$ of cases and conditions the long-term visual prognosis [8]. It can disappear in case of appropriate treatment or evolve towards micro-cystic degeneration or lead to the formation of a macular hole, most often lamellar [9]. This unusual complication of Behçet's disease is the subject of very little study. In Senegal we have not found any related publications.

\section{Conclusion}

During Behçet's disease, it is important to examine the macula for macular lesions as it may progress to a macular hole and cause loss of visual function. Close collaboration between internist, dermatologist and ophthalmologist is essential for early diagnosis and adequate management.

\section{References}

1) Shimizu T (1974) Behçet's syndrome - Lists of clinical and epidemical statistics. Nippon Rinsho 32: $2093-2102$.

2) Streho M, Aoub A (2010) Maladie de Behçet. Les uvéites. In : Rapport de la SFO 757.

3) Atmaca L (1989) Fundus changes associated with Behçet's disease. Graefes Arch Clin Exp Ophthalmol 227: 340 - 344.

4) Daghfous $M$, Ammar $M$, Kamoun $M$ (1980) Aspects cliniques et évolution de la maladie d'Adamantiades Behçet en Tunisie : à propos de 41 cas. J Fr Ophtalmol 3: 463 - 468.

5) Brézin A (2010) Les uvéites : Rapport de la SFO 757.

6) Azizlerli G et al. (2003) Prevalence of Behçet's disease in Istambul tyrky. Int J Dermatol 42: 803 - 806.

7) Nussenblatt R (1986) Macular alterations secondary to intraocular inflammatory disease. Ophthalmology 93: 984 - 988.

8) Shikano S, Shimizu K (1968) Atlas of fluorescence Fundus angiography. Tokyo Igaku Shain Publ.

9) Khairallah M, Ben Yahia S, Kahloun R (2012) Eil et maladie de Behçet; J Fr Ophtalmol 35: 826 837. 


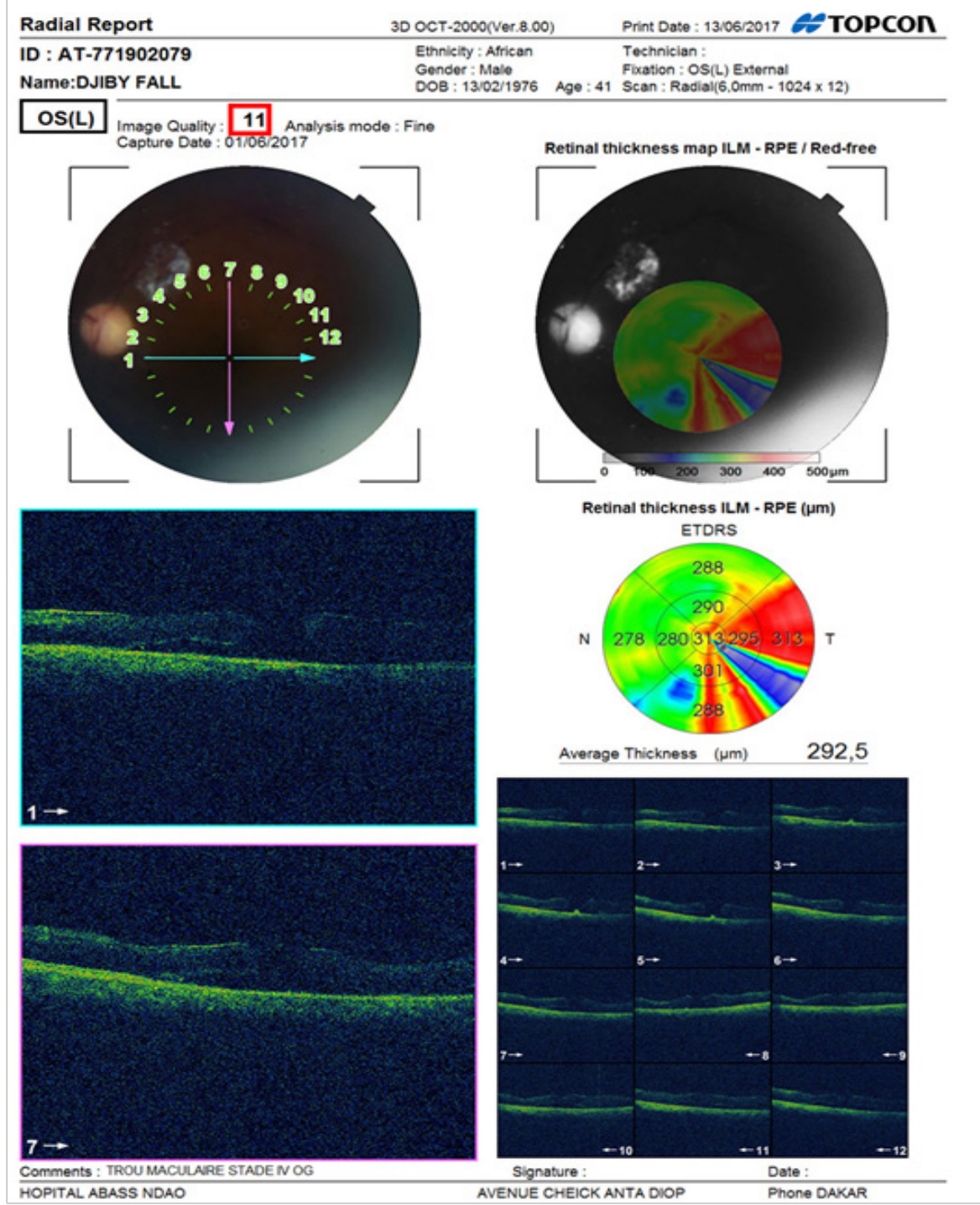

Figure 1: Optical coherence tomography showing a macular hole in the left eye of our patient

Submit your manuscript to a JScholar journal and benefit from:

g Convenient online submission

- Rigorous peer review

- Immediate publication on acceptance

g Open access: articles freely available online

g High visibility within the field

- Better discount for your subsequent articles Submit your manuscript at http://www.jscholaronline.org/submit-manuscript.php 